\title{
STUDIES ON SUBLIMATION COEFFICIENT OF ICE
}

\author{
Ryozo TOEI, MoRIo OKAZAKI AND MASASHI ASAEDA* \\ Department of Chemical Engineering, Kyoto University, Kyoto, 606
}

\begin{abstract}
Sublimation rate of ice into rarefied gases is studied experimentally between two concentric spheres in the range of sublimating surface temperature of $-50^{\circ} \mathrm{C} \sim-30^{\circ} \mathrm{C}$, and the range of stagnant gas pressure at the condensing surface of $0 \sim 1 \mathrm{mmHg}$.

The results are compared with the analytical results obtained with the two-sided Maxwellian distribution functions. Applying the theoretical results to mass transfer through the gaseous phase, a sublimation coefficient of ice of about 0.3 is obtained near $-30^{\circ} \mathrm{C}$ and 0.7 near $-50^{\circ} \mathrm{C}$. The effect of the partial pressure of stagnant gas on experimental measurements of the sublimation coefficients is also discussed.
\end{abstract}

\section{Introduction}

The study of sublimation rate of ice under vacuum is interesting as a basic study of freeze-drying as well as of mass transfer through rarefied gases. As is well known, the equation of diffusion which holds under atmospheric pressure cannot be applied to mass transfer through rarefied stagnant gases or under pressure so decreased that the mean free path of molecules is comparable with the characteristic length of the diffusion space. Under these conditions the assumption of quasi-equilibrium between the gas phase and the evaporating surface no longer holds and, therefore, new boundary conditions concerned with the rate of phase change must be taken into account as well as the rate of diffusion through stagnant gas. Under such conditions the rate of phase change can be expressed by the well-known Hertz-Knudsen equation,

$$
G=a\left(\frac{M}{2 \pi R T_{s}}\right)^{1 / 2}\left(P_{s}-P\right)
$$

where $a$ is the evaporation (sublimation) coefficient. This evaporation (sublimation) coefficient becomes an important controlling factor for mass transfer with evaporation, especially when the diffusional resistance of the gaseous phase is so small that the mass transfer rate approaches its maximum rate. And if the evaporation coefficient is very small, evaporation resistance cannot be neglected even when the diffusional resistance is relatively large.

Theoretical studies of these evaporation (sublimation) coefficients of liquids and solids have been made by many investigators ${ }^{8,10,11,13,15,19,29)}$ considering various models of evaporating surface. The most successful theory for the evaporation coefficients of liquids is that of Eyring et al. ${ }^{13)}$, who proposed the free angle ratio of liquids, which was found to be

Received November 18, 1974. equal to the evaporation coefficient ${ }^{19,29)}$. As for the sublimation coefficient of solids, none of them can be used to estimate successfully the sublimation coefficients for practical use.

There are also a number of experimental investigations of the evaporation (sublimation) coefficients ${ }^{2,7,9}$, $14,20,23,26)$ of various kinds of substances, some of which are listed in Table 1. In Table 2 are shown the experimental results of the sublimation coefficient of ice. As shown in this table, some of them are nearly equal to 1.0 at temperatures below $-60^{\circ} \mathrm{C}$, and the coefficient seems to decrease as the temperature increases. But this is not clear from these data. The scattering of these values may be considered to be due to the unsuitable estimation of mass transfer in the gaseous phase (effect of stagnant gas which might exist and the uncertainty of the diffusing space)

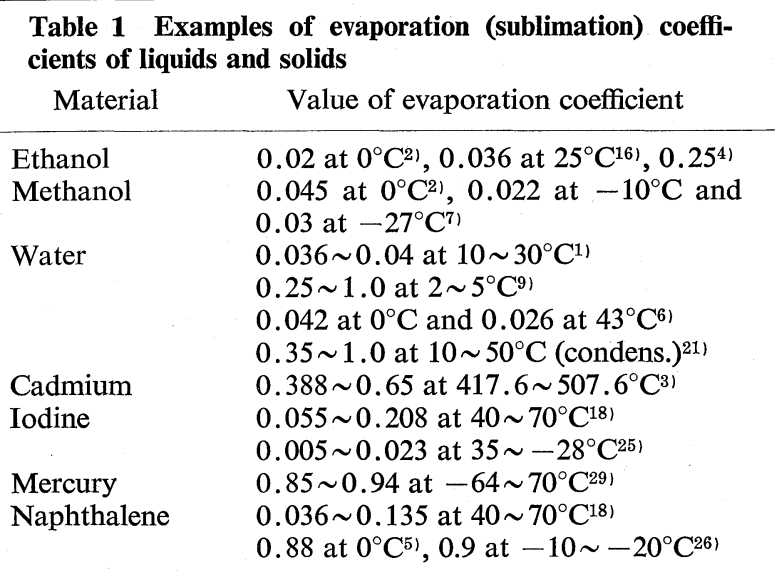

Table 2 Sublimation coefficient of ice

$\begin{array}{ll}0.94 \pm 0.06 & \text { at }-58 \sim-60^{\circ} \mathrm{C}^{28)} \\ \text { nearly unity } & \text { at }-60 \sim-40^{\circ} \mathrm{C}^{17)} \\ 0.67 & \text { at }-80 \sim-60^{\circ} \mathrm{C}^{22)} \\ 0.6 \sim 0.4 & \text { at }-80 \sim-60^{\circ} \mathrm{C}\left(\text { condensation }^{22)}\right) \\ 0.83 \pm 0.12 & \text { at }-128^{\circ} \mathrm{C}^{22)} \\ 0.0144 & \text { at }-13 \sim-2^{\circ} \mathrm{C}^{6)} \\ 0.0009 \sim 0.6 & \text { at } 0 \sim-50^{\circ} \mathrm{C}^{12)}\end{array}$




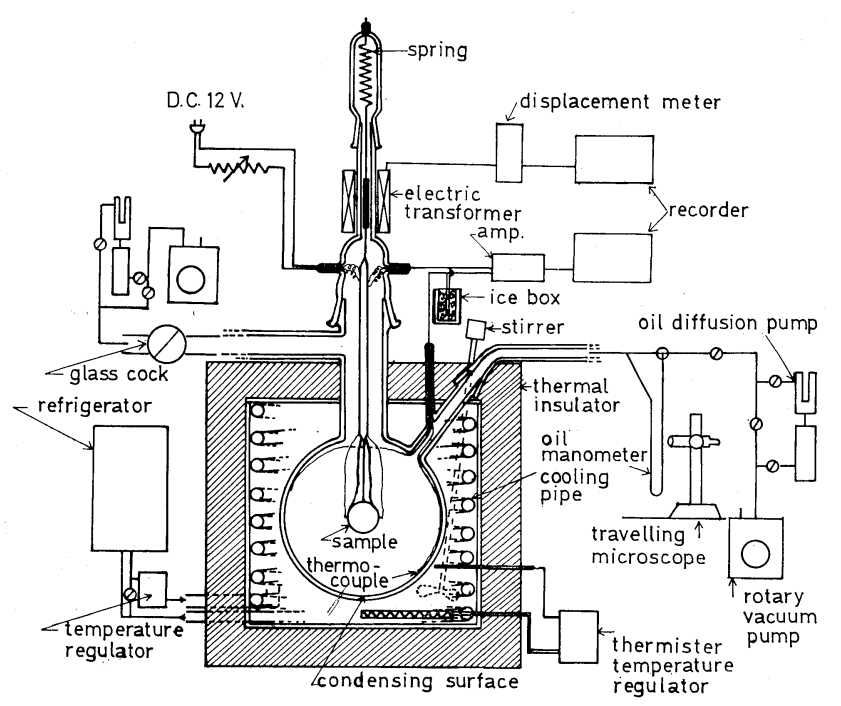

Fig. 1 Schematic diagram of apparatus

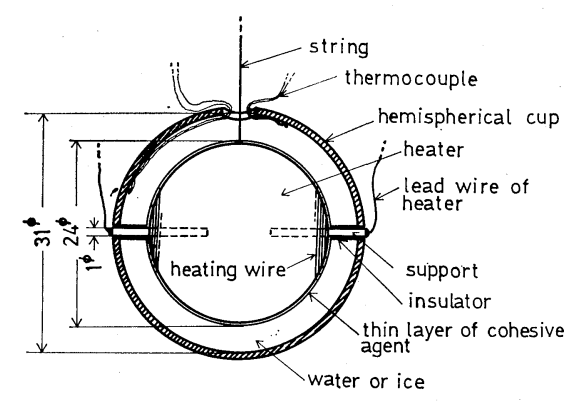

Fig. 2 Details of sample sphere of ice

in addition to the difficulty of temperature measurement of the sublimating surface.

In the present work the sublimation rate of ice under vacuum is studied experimentally under various partial pressures of inert gas (air). From the experimental results the sublimation coefficient of ice is obtained by applying the theoretical results of the two-sided Maxwellian distribution functions to mass transfer in the gaseous phase. The effect of the partial pressure of stagnant gas on the experimental estimation of evaporation coefficients is also discussed.

\section{Experimental Apparatus and Procedures}

A schematic diagram of the apparatus is shown in Fig. 1. Sublimation occurs at the surface of the inner sphere (about $31 \mathrm{~mm}$ diam.) of ice and the vapor diffuses through the stagnant gas (air) and then condenses on the inner surface of the outer sphere $(150 \mathrm{~mm}$ I.D.) of glass, the temperature of which is kept constant during the measurements. These two spheres are made concentric before the experiments. The details of the heater in the sample of ice sphere are shown in Fig. 2. The heater consists of a heating wire $(0.1 \mathrm{~mm}$ diam.) coiled around a glass sphere.
The wire is fixed with a thin layer of cohesive agent. A stainless steel pipe ( $1 \mathrm{~mm}$ O.D.) is attached as shown in this figure to support the heater in the center of the ice sphere when the sample sphere of ice is made. The heater is set in a pair of hemispherical cups (31 mm I.D.) of brass so as to coincide with the centers of these spheres. Two pairs of copperconstantan thermocouples $(0.06 \mathrm{~mm}$ diam.) are fixed near the inner surface of the brass cups (depth from inner surface of the cup is less than $1 \mathrm{~mm}$ ) before the pair of cups are put together. Distilled water is poured into the space between these two spheres from a small hole in the top of the brass sphere, shown in Fig. 2, and then cooled slowly to make an ice sphere. The sublimation rates of the ice sphere are measured by the weighing mechanism, shown in Fig. 1, which consists of a spring, an electric transformer and a displacement meter. The temperature of the condensing surface is measured by two pairs of thermocouples $(0.29 \mathrm{~mm}$ diam.) attached to the inner surface of the outer sphere, where a small amount of ice is condensed before the experiments. The temperature of this surface is kept constant (within $\pm 0.05^{\circ} \mathrm{C}$ ) during each measurement by circulating a coolant. The temperature of the sublimating surface is also measured by two pairs of thermocouples mounted near the surface of the ice sphere as described above.

After the sample of ice sphere frozen as described above was cooled further by coolant from a refrigerator the temperature of which was kept constant, evacuation was carried out until a definite pressure was attained. Then the glass cock was closed and heating was started. After a quasi-steady state was attained, measurements of surface temperature, rate of sublimation and pressure were made. After the measurements the ice sphere was taken out of the chamber to measure its diameter and to check if the junctions of the thermocouples were just at the surface or not.

Embedment of the thermocouple in the ice sphere will cause a direct error in readings of the surface temperature. For example, if the junction is at a depth of $0.1 \mathrm{~mm}$ from the surface the temperature reading will be higher than the temperature of the sublimating surface by about $0.1^{\circ} \mathrm{C}$ for the worst case. Accordingly, it was strictly checked if the junction was just on the surface of the ice sphere or not. And the temperature distribution of the sublimating surface was checked by mounting two thermocouples in the thin layer near the surface. The maximum difference in the readings of these thermocouples was about $20 \%$ of the temperature difference between the sublimating and condensing surfaces when both thermocouples were confirmed to be just on the surface. 


\section{Discussion of the Results}

The mechanism of mass transfer in the gaseous phase must be clearly known to determine sublimation (evaporation) coefficients. If it is not, the ambiguity of the rate of mass transfer in the gaseous phase causes uncertainty in the value of sublimation (evaporation) coefficients, because these coefficients cannot be determined experimentally without mass transfer in the gaseous phase.

Until now two models of mass transfer under vacuum have been proposed, one of which is the classical "series resistance model ${ }^{23)}$ ", where the resistances of evaporation and diffusion are considered in series. The other is the one derived from the two-sided Maxwellian distribution functions ${ }^{26}$. It was found that the results of these two models completely coincided for mass transfer between two infinite parallel plates ${ }^{27)}$, but not for the case of curved surfaces such as was the case in the present work.

In this paper the results obtained from the model of the two-sided Maxwellian distribution functions is used to estimate the sublimation coefficient. According to this model, the mass transfer rate can be expressed $a^{26)}$

$$
N_{A I}=\left(\frac{m_{A}}{2 \pi k T}\right)^{1 / 2} \gamma
$$

where $\gamma$ is to be obtained from the following equation:

$$
\begin{aligned}
P_{A I}-P_{A I I} & =\left[\frac{1}{a}+\left\{\frac{1-a}{a}\left(\frac{1}{\bar{R}^{*}}\right)^{2}\right\}\right] \gamma \\
& +P_{B 1 I I}\left[1-\exp \left\{-\zeta \gamma\left(1-\frac{1}{\bar{R}^{*}}\right)\right\}\right]
\end{aligned}
$$

where

$$
\begin{aligned}
P_{B 1 I I} & =P_{m}-P_{A I I}-\frac{1}{a}\left(\frac{1}{\bar{R}^{*}}\right)^{2}, \\
\zeta & =\frac{1}{2 P_{t} D}\left(\frac{2 k T}{\pi m_{A}}\right)^{1 / 2} \text { and } \bar{R}^{*}=\frac{R_{I I}}{R_{I}}
\end{aligned}
$$

In the absence of stagnant gases Eq. (2) can be written as

$$
N_{A I}=\frac{1}{\frac{1}{a}+\left(\frac{1-a}{a}\right)\left(\frac{1}{\bar{R}^{*}}\right)^{2}} \cdot\left(\frac{m_{A}}{2 \pi k T}\right)^{1 / 2}\left(P_{A I}-P_{A I I}\right)
$$

The experimental results of the sublimation coefficient of ice calculated by Eq. (4) are shown in Table 3, which also shows the experimental results at various partial pressures of stagnant gas (air) (group B). The vapor pressure of ice was measured as shown in

\begin{tabular}{|c|c|c|c|c|c|c|}
\hline \multicolumn{7}{|c|}{ Group A $\quad\left(P_{B 1 I I}=0\right)$} \\
\hline $\begin{array}{l}\text { Run } \\
\text { No. }\end{array}$ & $\begin{array}{c}T_{I} \\
{\left[{ }^{\circ} \mathrm{C}\right]}\end{array}$ & $\begin{array}{c}T_{I I} \\
{\left[{ }^{\circ} \mathrm{C}\right]}\end{array}$ & $\underset{[\mu \mathrm{Hg}]}{\Delta P}$ & \multicolumn{2}{|c|}{$\begin{array}{c}N_{A I} \times 10^{5} \\
{\left[\mathrm{~g} / \mathrm{cm}^{2}\right.} \\
\cdot \mathrm{sec}]\end{array}$} & $\stackrel{a}{-}]$ \\
\hline 1 & -40.02 & -40.70 & \multicolumn{2}{|c|}{7.2} & 5.60 & 0.51 \\
\hline 3 & -39.13 & -40.15 & \multirow{2}{*}{\multicolumn{2}{|c|}{$\begin{array}{r}11.3 \\
8.2\end{array}$}} & 7.98 & 0.45 \\
\hline 19 & -39.95 & -40.75 & & & 6.78 & 0.52 \\
\hline 20 & -39.02 & -40.05 & \multicolumn{2}{|c|}{$\begin{array}{r}0.2 \\
11.4\end{array}$} & 7.37 & 0.41 \\
\hline 32 & -49.10 & -50.38 & \multicolumn{2}{|c|}{5.1} & \multirow{2}{*}{$\begin{array}{l}5.71 \\
7.26\end{array}$} & 0.68 \\
\hline 33 & -36.56 & -37.05 & \multicolumn{2}{|c|}{7.4} & & 0.62 \\
\hline 43 & -33.35 & -33.85 & \multicolumn{2}{|c|}{9.0} & 7.22 & 0.53 \\
\hline 45 & -27.35 & -27.63 & 13 & .0 & .93 & 0.30 \\
\hline 46 & -28.95 & -29.40 & & & .85 & 0.30 \\
\hline & up B & & & & & \\
\hline $\begin{array}{l}\text { Run } \\
\text { No. }\end{array}$ & $\begin{array}{c}T_{I} \\
{\left[{ }^{\circ} \mathrm{C}\right]}\end{array}$ & $\begin{array}{c}T_{I I} \\
{\left[{ }^{\circ} \mathrm{C}\right]}\end{array}$ & $\begin{array}{c}\Delta P \\
{[\mu \mathrm{Hg}]}\end{array}$ & $\begin{array}{c}N_{A I} \times 10 \\
{\left[\mathrm{~g} / \mathrm{cm}^{2}\right.} \\
\cdot \mathrm{sec}]\end{array}$ & $\begin{array}{r}K_{g} \times 10^{3} \\
{\left[\mathrm{~g} / \mathrm{cm}^{2} \cdot \mathrm{se}\right.} \\
\cdot \mathrm{mmHg}]\end{array}$ & $\begin{array}{ll}P_{B 1 I I} \\
\text { ec }[\mu \mathrm{Hg}] \\
\text { ] }]\end{array}$ \\
\hline 34 & -29.75 & -30.50 & 21.0 & 5.04 & 2.40 & 33 \\
\hline 35 & -29.65 & -30.53 & 26.0 & 4.94 & 1.90 & 26 \\
\hline 36 & -29.40 & -29.80 & 13.0 & 5.24 & 4.03 & 18 \\
\hline 37 & -28.05 & -28.45 & 14.0 & 5.33 & 3.81 & 4 \\
\hline 38 & -30.29 & -30.88 & 16.0 & 5.47 & 3.42 & 10 \\
\hline 39 & -29.45 & -30.01 & 20.0 & 7.94 & 3.47 & 16 \\
\hline 40 & -30.80 & -31.47 & 17.0 & 6.90 & 4.07 & 10 \\
\hline 41 & -31.45 & -31.95 & 12.0 & 7.21 & 6.55 & 7 \\
\hline 44 & -30.53 & -31.20 & 17.0 & 7.19 & 4.23 & 3 \\
\hline 2 & -39.65 & -40.52 & 9.1 & 7.84 & 8.62 & 3 \\
\hline 4 & -38.90 & -40.75 & 20.1 & 1.68 & 0.836 & 140 \\
\hline 5 & -38.15 & -40.45 & 26.5 & 1.12 & 0.423 & 332 \\
\hline 6 & -36.30 & -40.60 & 54.9 & 1.41 & 0.357 & 467 \\
\hline 7 & -36.35 & -40.01 & 58.0 & 1.12 & 0.193 & 607 \\
\hline 8 & -34.90 & -40.01 & 84.8 & 1.33 & 0.157 & 756 \\
\hline 9 & -39.65 & -40.75 & 11.4 & 7.37 & 6.47 & 6 \\
\hline 10 & -40.25 & -41.40 & 11.3 & 4.31 & 3.81 & 26 \\
\hline 11 & -39.70 & -41.90 & 21.8 & 2.59 & 1.19 & 82 \\
\hline 12 & -40.05 & -41.85 & 17.4 & 4.31 & 2.48 & 40 \\
\hline 13 & -40.60 & -41.85 & 11.8 & 6.49 & 5.50 & 9 \\
\hline 14 & -40.65 & -41.65 & 9.6 & 6.48 & 6.75 & 12 \\
\hline 15 & -40.45 & -41.40 & 9.3 & 6.25 & 6.72 & 10 \\
\hline 16 & -40.45 & -41.00 & 5.4 & 3.07 & 5.69 & 3 \\
\hline 17 & -40.10 & -40.98 & 8.7 & 2.51 & 2.89 & 43 \\
\hline 21 & -48.15 & -49.80 & 7.1 & 2.75 & 3.87 & 21 \\
\hline 22 & -46.85 & -49.80 & 13.5 & 2.73 & 2.02 & 62 \\
\hline 23 & -46.90 & -49.80 & 13.3 & 2.47 & 1.86 & 6 \\
\hline 24 & -46.75 & -49.70 & 13.7 & 3.79 & 2.77 & 19 \\
\hline 26 & -47.70 & -49.85 & 9.5 & 3.79 & 3.99 & 25 \\
\hline 27 & -48.40 & -49.85 & 6.2 & 4.90 & 7.90 & 6 \\
\hline 28 & -48.20 & -50.23 & 8.7 & 5.10 & 5.86 & 8 \\
\hline 29 & -47.99 & -50.20 & 9.6 & 5.40 & 5.63 & 13 \\
\hline 30 & -48.33 & -50.38 & 8.5 & 4.52 & 5.23 & 12 \\
\hline 31 & -48.85 & -50.23 & 5.8 & 5.73 & 9.89 & 5 \\
\hline
\end{tabular}
Fig. 3 and was used in the calculations of these values. It can be seen from the results of group (A) in Table 3 that the sublimation coefficient of ice depends on the temperature. It decreases as the temperature
Table 3 Experimental results

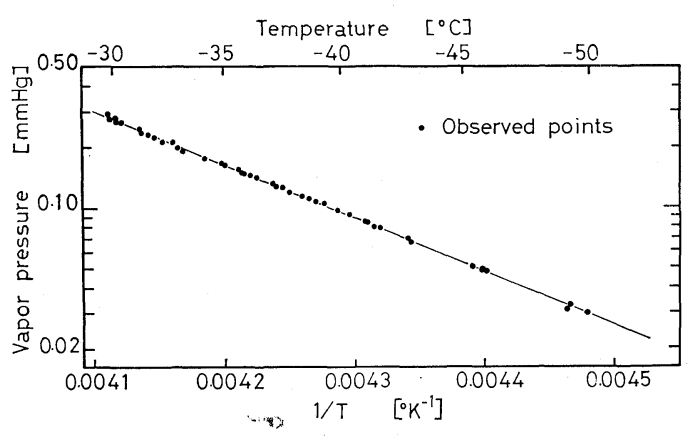

Fig. 3 Observed vapor pressure 


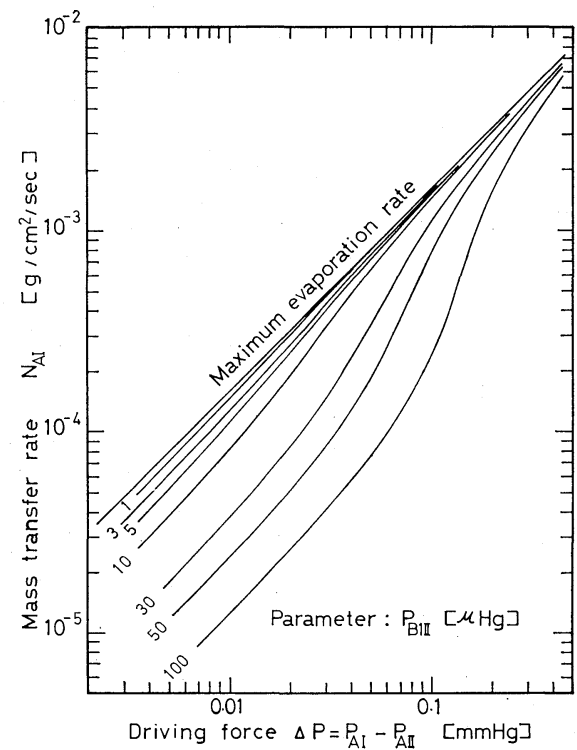

(calculated from Eqs. (2) and (3) for $a=1.0$ )

Fig. 4 Effects of partial pressure of stagnant gas (air) and driving force on mass transfer (ice)

increases, as reported by Stern et al. ${ }^{25)}$ for iodine. And it can be guessed from the authors' results that the sublimation coefficient of ice approaches the results of Tschudin ${ }^{28)}$ and others ${ }^{22)}$, or 1.0 as the temperature decreases. At rather high temperatures Delany et al.$^{6)}$ and Kawamura ${ }^{12)}$ reported sublimation coefficients of the order of $10^{-2} \sim 10^{-3}$, which seems too small judging from the relatively slight dependency of the coefficient on temperature found by the authors.

In general it is very difficult to obtain the evaporation (sublimation) coefficients of materials such as ice the vapor pressure of which sharply changes with temperature, because the temperature difference between condensing and evaporating surfaces is very small at moderate evaporation rates. And at the moderate evaporation rates even a small partial pressure of inert gas makes a large error in evaporation rate or in experimental estimation of the evaporation (sublimation) coefficient as shown in Fig. 4 (calculated from Eqs. (2) and (3) by putting $a$ to be 1.0), where the mass transfer rate is shown with a parameter of the partial pressure of the inert gas. It can be seen from this figure that the mass transfer rate approaches the maximum evaporation rate as the driving force $\Delta P$ increases and the effect of the partial pressure of the inert gas on mass transfer rate decreases. At the moderate evaporation rates near $N_{A I}=10^{-5} \sim 10^{-4} \mathrm{~g} / \mathrm{cm}^{2} \cdot \mathrm{sec}$, however, the effect of partial pressure on mass transfer is large and cannot be neglected. If the effect of partial pressure of the stagnant gas of $0.005 \mathrm{mmHg}$ were neglected, for example, then the apparent evaporation coefficient might be smaller than 0.7 (in spite of the real value of

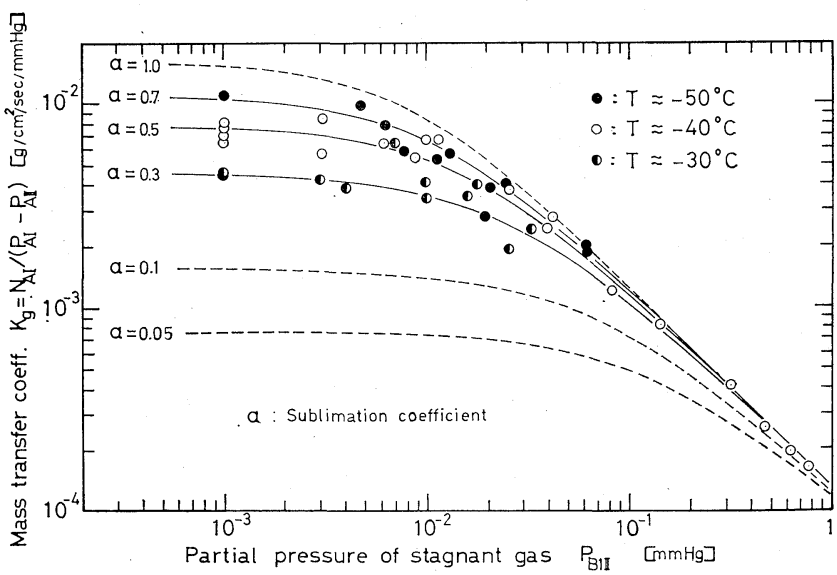

Fig. 5 Comparison of experimental results of mass transfer rate with theoretical ones in the presence of stagnant gas (air)

the coefficient $a$ of 1.0) when the mass flux is of the order of $10^{-5} \mathrm{~g} / \mathrm{cm}^{2} \cdot \mathrm{sec}$. Therefore the partial pressure of stagnant gas must be precisely measured to obtain the evaporation coefficient experimentally. The effect of the partial pressure of stagnant gas and the evaporation coefficient on mass transfer is more clearly shown in Fig. 5 with the parameter of the evaporation coefficient. The ordinate is the mass transfer coefficient $K_{g}$, defined here as $K_{g}=N_{A I} /$ $\left(P_{A I}-P_{A I I}\right)$ for convenience. In the same figure the experimental results are shown. The values of group (A) in Table 3 are plotted on $P_{B 1 I I}=0.001 \mathrm{mmHg}$ for reference. The solid lines are the theoretical curves corresponding to the values of the sublimation coefficient of 0.7, 0.5 and 0.3 . It can be seen from this figure that the sublimation coefficient plays an important role in mass transfer through a highly rarefied stagnant gas, but it does not do so at relatively large partial pressure of stagnant gas (larger than about $0.1 \mathrm{mmHg}$, for example) if the sublimation coefficient is relatively large (larger than about 0.5 in the present case).

Judging from the finding that the experimental results near the temperatures $-50^{\circ} \mathrm{C},-40^{\circ} \mathrm{C}$ and $-30^{\circ} \mathrm{C}$ are in relatively good accord with the theoretical results for the sublimation coefficients of 0.7 , 0.5 and 0.3 respectively, the values of sublimation coefficient of ice obtained here are considered to be reliable.

\section{Conclusion}

Mass transfer rates through a rarefied stagnant gas were measured between two concentric spheres. The sublimation coefficient of ice was obtained from experimental results to be about 0.3 near $-30^{\circ} \mathrm{C}$ and 0.7 near $-50^{\circ} \mathrm{C}$. Using these results of the sublimation coefficient, the experimental results were in relatively good accordance with the theoretical results 
in the presence of the stagnant gas. It was also found that the partial pressure of the stagnant gas significantly affects the mass transfer rate, and it cannot be neglected in the experimental estimation of the evaporation (sublimation) coefficient, even if the partial pressure is of the order of $10^{-3} \mathrm{mmHg}$.

\section{Acknowledgment}

This research was supported in part by Grant-in-Aid for Scientific Research from the Ministry of Education (No. 885179, 1973) and by the Takeda Science Promotion Foundation, for which the authors express their sincere thanks.

\section{Nomenclature}

$$
\begin{aligned}
& a \quad=\text { evaporation (sublimation) coefficient } \\
& D \quad=\text { diffusion coefficient } \\
& G \quad=\text { evaporation rate } \\
& k=\text { Boltzmann constant } \\
& M \quad=\text { molecular weight } \\
& m_{A} \quad=\text { mass of a molecule } \\
& N_{A I} \quad=\text { mass flux per unit area of evaporating surface } \\
& P \quad=\text { (partial) pressure just above evaporating surface } \\
& P_{A I}=\text { saturated vapor pressure at temperature } T_{I} \text { of }
\end{aligned}
$$

(C.G.S. units are used.)

\section{Literature Cited}

1) Alty, T.: Phil. Mag., 65, 82 (1933).

2) Baranaev, M.: Zhrnal Fizi. Khim., 13, 1635 (1939).

3) Bennewitz, K.: Ann. Phys., 59, 193 (1919).

4) Bucka, H.: Z. Phys. Chem., 195, 260 (1950).
5) Burrows, G.: J. Appl. Chem., 7, 375 (1957).

6) Delaney, L. J., N. J. Psaltis and L.C. Eagleton: Chem. Eng. Sci., 19, 105 (1964).

7) Delaney, L. J., R. W. Houston and L. C. Eagleton: ibid., 20, 607 (1965).

8) Eyring, H., F. M. Wallas and E. M. Eyring: "Condensation and Evaporation of Liquids and Solids", Gordon and Breach Sci. Pub., Inc. (1964).

9) Hickman, K. C. D.: Ind. Eng. Chem., 46, 1442 (1954).

10) Hirth, J. P. and G. M. Pound: J. Chem. Phys., 26, 1216 (1957).

11) Hirth, J. P. and G. M. Pound: J. Phys. Chem., 64, 619 (1960).

12) Kawamura, Y.: Doctoral thesis, Tokyo Inst. Tech. (1961).

13) Kincaid, J. F. and H. Eyring: J. Chem. Phys., 6, 620 (1938).

14) Kitchener, S. A. and R. F. Strickland-Constable: Proc. Roy. Soc. (London), A245, 93 (1958).

15) Knacke, O., I. N. Stranski and G. Wolf: Z. Phys. Chem., 198, 157 (1951).

16) Knacke, O. and I. N. Stranski: Proc. Metal. Phys., 6, 181 (1956).

17) Kramer, H. and S. Stemerding: Appl. Sci. Res. (Hague), A3, 73 (1951).

18) Marcellen, R.: Compt. Rend., 158, 1674 (1919).

19) Mortensen, E. M. and H. Eyring: J. Phys. Chem., 64, 846 (1960).

20) Nabavian, K.: Z. Phys. Chem., A191, 284 (1942).

21) Nabavian, K. and L. A. Bromley: Chem. Eng. Sci., 18, 651 (1963).

22) Rutner, E., P. Goldfinger and J. P. Hirth: "Condensation and Evaporation of Liquids and Solids", Gordon and Breach Sci. Pub., Inc. (1964).

23) Sherwood, T. K. and N. E. Kooke: AIChE J., 3, 37 (1957).

24) Sherwood, T. K. and S. Johannes: ibid., 8, 590 (1962).

25) Stern, J. H. and N. W. Gregory: J. Phys. Chem., 61, 1226 (1957)

26) Toei, R., M. Okazaki, A. Uragami and Y. Takaki: $J$. Chem. Eng. Japan, 1, 125 (1968).

27) Toei, R., M. Okazaki and M. Asaeda: ibid., 4, 167 (1971).

28) Tschdin, K.: Helv. Phys. Acta, 19, 916 (1946).

29) Wyllie, G.: Proc. Roy. Soc. (London), A197, 383 (1949). 